\title{
Methods of Investigating the Use of Podcasting in Higher Education: A Review of Recent Studies
}

\author{
Gwendo John Oloo \\ Department of Technology Education \\ Moi University
}

\author{
Omwenga Elijah, Ph. D. \\ School of Computing and Informatics \\ University of Nairobi
}

\begin{abstract}
The high mobile penetration levels and the emergence of Web 2.0 technologies that include Wikis, Blogs, Podcasts, Screen cast, and Google Tools etc provide academic institutions with an opportunity to address some of the challenges they are facing in the provision of quality education given the ever increasing enrolment numbers. It is also important to note that the use of m-learning tools, if correctly conceptualized and built, constitutes an efficient complementary tool to the traditional teaching methods. The study reviewed journal articles with a view to examining the methods used in the investigating the adoption of podcasting in Higher Education. It was found that most studies were in the form of Action Research which either took an interpretive or positivist approach with the choice being guided by the objectives of the study. The review also points out to the need for orientation on use of podcasting at initial stages of its implementation.
\end{abstract}

\section{General Terms}

Podcasting, Mobile Learning,

\section{Keywords}

Podcasts, Mobile learning, Methods, Higher Education

\section{INTRODUCTION}

There has been an increase in demand for access and equity to Higher Education in Kenya and Africa at large. This has also been brought about by the increasing number of students graduating from secondary schools which has consequently led to corresponding pressures in the demand for higher education. According to a report by the National Association of State Universities and Land-Grant Colleges titled Challenges of Higher Education in Africa and Lessons of Experience for the Africa - U.S. Higher Education Collaboration Initiative the rate of increase in higher education enrollment in Africa in 2008 was doubling in five years, about $15 \%$ per year which is the highest in the world. The report also points out that Universities have not been able to meet these demands for higher education and are thus facing a decline in quality of education since they operate with overcrowded and deteriorating physical facilities, limited and obsolete library resources, insufficient equipment and instructional materials.

ICT has been identified has a critical in mitigating to mitigate some of these challenges. UNESCO's 2009 World conference on higher Education report pointed out that the application of ICTs to teaching and learning in Higher Education has a great potential to increase access, quality and success.

Mobile phones have been identified as an emerging technology that can be used to mitigate some of the challenges faced in higher Education. Mobile devices have been identified as a mainstream learning technology [19] used by about $71 \%$ as compared to Video content $(60 \%)$, Video conferencing (62\%), Rapid applications development tools
(62\%) Online assessment (63\%), Surveys and questionnaires (70\%) and Enterprise wide information services (70\%). The report also notes that mobile learning is projected to increase in the coming years. With this high mobile penetration levels and the emergence of Web 2.0 technologies that include Wikis, Blogs, Podcasts, Screencast, Google Tools etc Universities have an opportunity to address some of the challenges they are facing in the provision of quality education.

Web 2.0 has been viewed as an emergent key driver changing learning paradigms at academic institutions [20] and can make provide many resources to the learning environments as compared to the curriculum-oriented educational settings [9]. They are also of the view that by combining the three dimensions in education - learning, teaching, and assessing of Web 2.0 technologies in educational systems, both educators and learners are able not only to enhance their teaching and learning experiences with greater creativity, interactivity, and productivity but also to continuously retain their teaching and learning opportunities in and outside school with unprecedented affordances and sustainability of Web 2.0 applications.

Podcasts is one of the web 2.0 technologies that can be used in the education sector. A podcast has been defined as an audio file delivered over the Internet [21]. Taylor and Clark [22], identified three broad approaches to podcasting in higher education which include re-framed, complementary and supplementary podcasts. The use of these m-learning tools, if correctly conceptualized and built, constitutes an efficient complementary tool to the traditional teaching methods. The statistics clearly shows that there need to assess the potential of Mobile Learning particularly for Higher Education in Kenya.

\section{METHODS}

Researchers have adopted different methods when conducting studies to investigate the use of podcasting in Higher Education. Some of these methods are examined in this section.

Pegrum et. al [11] examined the effect of a podcasting on the examination performance of first-year chemistry undergraduate students by setting a task that involved student collaboration, contextualisation of content, and communication through creative podcasting. The research took a quantitative approach and was a partner to a previously reported qualitative research by the same researchers in which students' self-reported perceptions of the value of the podcasting task. Students were divided into groups of three by the unit coordinator based on their assigned benches in their practical lab classes with topics being assigned to them randomly. During the study, students were required to work collaboratively to create a 3-minute podcast on their assigned concept, explaining it clearly and comprehensively, but concisely, for a general educated audience with basic 
chemistry knowledge. Students submitted their completed podcasts through the WebCT learning management system [11]. During the week prior to end-of-semester examinations, these were made available to all students, who were asked to listen to and comment on six podcasts produced by their own practical class. Examination results were used as a source of empirical evidence of changes in understanding and retention that occurred for students who completed this task.

A research that sought to investigate effects of primer podcasts on stimulating learning from lectures [12] was conducted for undergraduate psychology students. The students were exposed to pre-lecture (primer) audio podcasts, throughout one semester. The purpose of these primer podcasts was to provide students with common background information. Their design [12] included the creation of podcasts that were about 5 minutes of length and consisted of an introduction to the main theories from the upcoming lecture, summary definitions of core concepts and examples. The podcasts were prepared by course lecturer and researchers and delivered to email to students two days before the lecture. Information was provided to learners on the availability of the podcasts with a evaluation questionnaires being used to collect data in relation to the perceived effects of the podcasts

In attempting to reach a deeper understanding of students' perception of podcasting, Khechine et. al [6] conducted a study aimed at examining the advantages and the disadvantages of podcast use. A case study with open-ended questions was conducted on students who had enrolled in an online undergraduate information system. Podcasts took the form of complementary podcasts. Data collection was through an online questionnaire. This research fitted interpretive approach because it attempted to understand the phenomena of podcast use by capturing human thought and behaviour [8].

Brookes [23] conducted an empirical study that sought to evaluate students' perceptions of the potential of podcasts to deliver formative feedback and the impact on their learning experience. A quantitative approach was adopted for the study as guided by the objectives which was to correlate students' use and perceptions of the podcasts with their perceived benefits and performance in a compulsory advanced undergraduate inter-disciplinary hospitality module. This was an Action Research was with weekly podcasts $n$ being developed on the basis of the teaching team and student experiences. A dedicated wiki was used to upload the podcasts whose details were different each week as guided by the student experiences. Students accessed the podcasts through subscription to i-tunes, via a personal computer or laptop, downloading to listen to at a later date. It is also important to note that prior information was given to students on what they should do with the podcasts, and why and how it could potentially help them, as recommended by Kirkwood and Price [7]. Data collection was through survey of students enrolled in the module. The podcasts were used to provide formative feedback very quickly after the learning activity took place [18]. Data was therefore collected on students' demographic profile; their attitudes towards technology and learning, and the grade achieved for the module; their use of podcasts throughout the module; their perceptions of the benefits of the podcasts and the difficulties they experienced; and their attitudes towards further use of podcasts in future modules.

A different approach was adopted by Alpay and Gulati [1] who presented an innovative podcasting approach in which there was a strong student-centred and student-led premise to foster and advance engineering education-related uses. Such an approach provides opportunities for experimental learning for students, fosters student motivation and active engagement to provide the sustainable delivery of a podcasting service $[1,13]$. The project consisted of five phases: recruitment; needs analysis; pilot studies; operations and management; guidelines and site finalization which is in line with principles of action research [1]. Like many other studies both quantitative and qualitative data was collected from participants through a questionnaire that distributed via email. The need for prior orientation on podcasting was also incorporated in the study where a 2-hour training session was given by a professional broadcaster from BBC World Service on podcasting technology and practice, science communication and interview methods.

Ng'ambi and Lombe [10] employed two case studies to develop an approach for using podcasts to enhance student learning. The study adopted an interpretive approach to investigate how students enrolled on a blended postgraduate programme in Educational Technology used podcasts for reflective learning. The interpretive approach allows researchers to view participants in a study as active knowledge constructors within their contexts [24]. Access to the podcasts was through downloads from a server to mobile devices and MP3 players. Case studies were conducted on two groups, one with podcasts being tightly coupled into pedagogy i.e. earning tasks were designed such that students were required to listen to podcasts in order to complete the tasks while the second case was loosely coupled. Data was gathered from two main sources, namely face-to-face interviews with students and access logs generated by Vula online collaboration and learning environment [10]

In investigating a podcast learning project integrated into an English speaking and listening class for the purpose of promoting extensive listening and fostering independent learning a study was conducted in an English speaking and listening course at a public university in southern Taiwan[16]. This project was designed to be closely integrated with the coursework. The need for orientation on the use and adoption of podcasting was also given during the study $[1,16]$. A unique aspect of this study was the use of teacher-directed podcast sessions which were designed with the aim of exposing students to a wide variety of online audio resources [16]. This approach of using teacher demonstrated learning materials was well suited for the study that was for an English speaking and listening skills.

Questionnaire responses, student podcast diaries and the teacher-researcher's notes on students' Podcasting Learning project presentations were the main sources of data [16]. The questionnaire collected data on students' prior podcasting experiences and current podcasting practices, factors affecting students' podcast subscriptions and supplementary activities that students performed to facilitate podcast listening. Qualitative and quantitative approaches were used during the data analysis phase of the study.

Chan et. al [3] also conducted a study to investigate the use of podcasting by language teachers as a tool for delivering educational content and to encourage learning outside of the traditional classroom. The aim of their study was to explore the effective podcast design and students' perceptions of and attitudes towards this medium. Post-project evaluation questionnaires we used to seek answers to the research questions with both qualitative and quantitative data being collected. Quantitative data included technology available to students for podcast access (e.g. PC and/or MP3 player, and Internet resources), previous experience with (educational) 
podcasting, podcast usage (such as frequency and locations of podcast access, and the hardware/software used), students' perceptions of the podcast's usefulness and quality, including its design, content and technical production, as well as their attitudes towards podcast-based learning [3]. Qualitative data collected was through open-ended questions to elicit qualitative data on students' perceptions, suggestions for improvements and reasons for listening.

\section{DISCUSSIONS}

The findings reveals that most studies conducted on podcasting were in the form of Action research which Watts, 1985 describes as a process in which participants examine their own educational practice systematically and carefully, using the techniques of research. It is also evident that the need for orientation on use and adoption of podcasting at the initial stages of the research is critical to its success in an Education setting $[1,16]$.

From the study it has been noted the implementation of podcasting in education involves the creating and posting of podcasts. However different methods have been used to achieve this i.e. submission through Web Learning Systems $[11,12]$, dedicated wikis [23] or through sharing through email and secondary storage $[3,16]$. The need to provide different access modes to the podcasts to learners is an issue that must also be addressed by researchers to ensure the success of the implementation. Brookes [23] achieved this effectively through use of itunes, Personal Computers, laptops and also offline.

Podcasts created in the different studies were either student generated $[1,10,11]$ or lecturer generated $[6,12,16]$. According to Alpay and Gulati [1] a student-led podcasting project provides an innovative communication format for student engagement and involvement in educational topics, debates and developments among students and staff. There is a growing acceptance of the importance of student-centered and heuristic learning, and the emergence of mobile devices as learning tools [4]. Student generated podcasts encourages them to engage in metacognitive thinking about learning [24]. However lecturer generated podcasts has been popular in the teaching of languages $[3,16]$.
Table 1: Types of podcasts prepared

\begin{tabular}{|l|l|}
\hline \multicolumn{1}{|c|}{ Type } & \multicolumn{1}{|c|}{ Studies } \\
\hline Student Generated & $\begin{array}{l}\text { Brookes[23]; Alpay \& Gulati [1]; } \\
\text { Pegrum et. al [11] }\end{array}$ \\
\hline $\begin{array}{l}\text { Teacher-directed } \\
\text { podcast }\end{array}$ & $\begin{array}{l}\text { Yeh [16]; Popova et. al [12]; } \\
\text { Khechine et. al [6], Chan et. al [3] }\end{array}$ \\
\hline
\end{tabular}

Both the quantitative positivist approach [12, 23] and the Qualitative interpretive approach $[6,11]$ has been adopted in investigating the use of podcasting in Education. Recent studies have pointed out the adoption of a mixed approach that incorporates both the quantitative and qualitative methods $[1,16]$. It is clear that the choice of approach should be guided by the objectives of the study.

Table 2: Type of research used in studies on podcasting

\begin{tabular}{|l|l|}
\hline \multicolumn{1}{|c|}{ Type } & \multicolumn{1}{c|}{ Studies } \\
\hline Quantitative & $\begin{array}{l}\text { Brookes [23]; Pegrum et. al [11], Popova et. } \\
\text { al.[12], Khechine et. al [6] }\end{array}$ \\
\hline Qualitative & Khechine et. al [6], \\
\hline $\begin{array}{l}\text { Mixed } \\
\text { approach }\end{array}$ & $\begin{array}{l}\text { Alpay and Gulati [1], Ng'ambi and Lombe } \\
\text { [10], Yeh [16], Chan et. al [3] }\end{array}$ \\
\hline
\end{tabular}

Different data collection tools have been used in the studies on podcasting with questionnaires being the most popular both for collecting quantitative and qualitative data $[1,2,6$, 12, 23]. It is important to note that questionnaires have also been used together other methods of data collection like podcasts diaries and researcher's notes [16]. Individual interviews have also been used to verify findings from the analysis of the questionnaire data [3].. Face to face interviews and podcasts access logs have also been used as data collection methods [10]. A study examined the effects of a podcasting on the examination performance and examination results data were the main source of data [11].

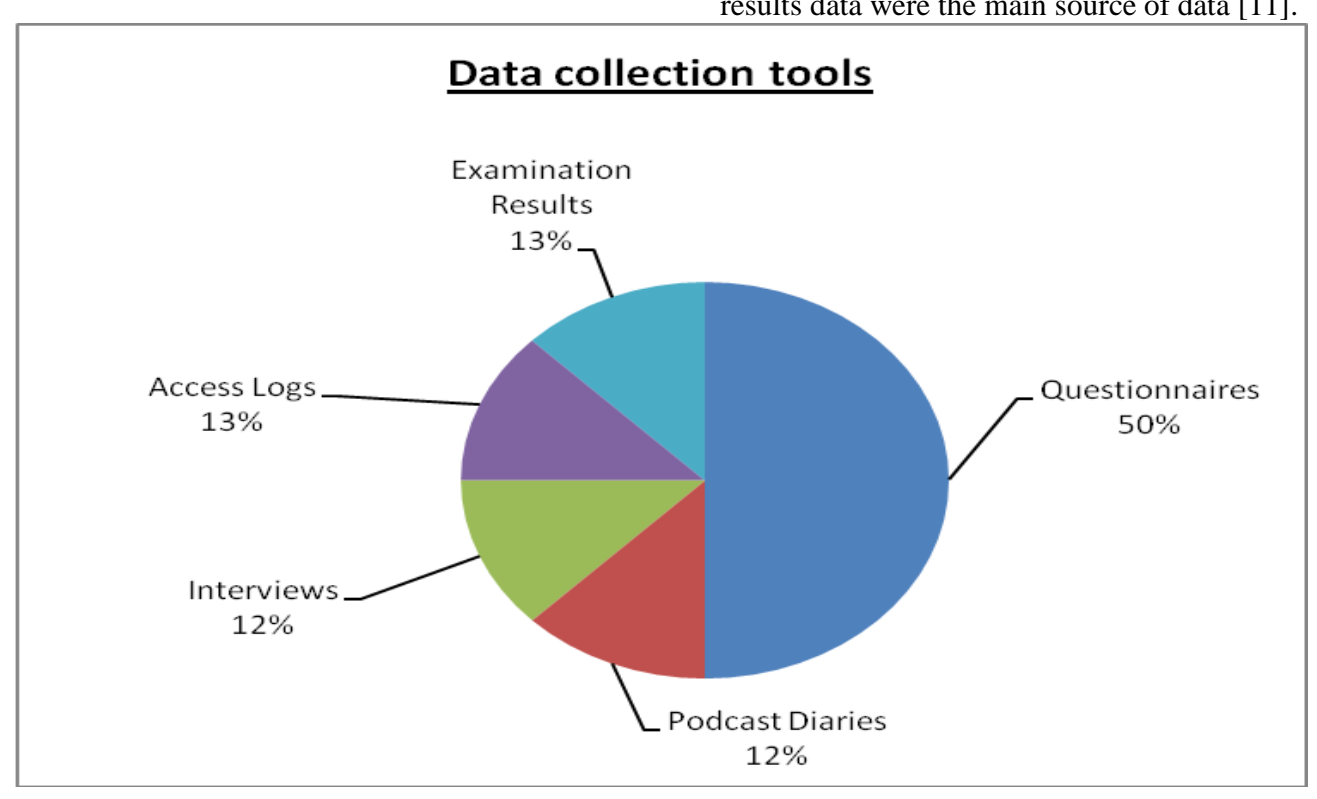

Figure 1: Data collection tools used in to investigate podcasting for some sampled studies 


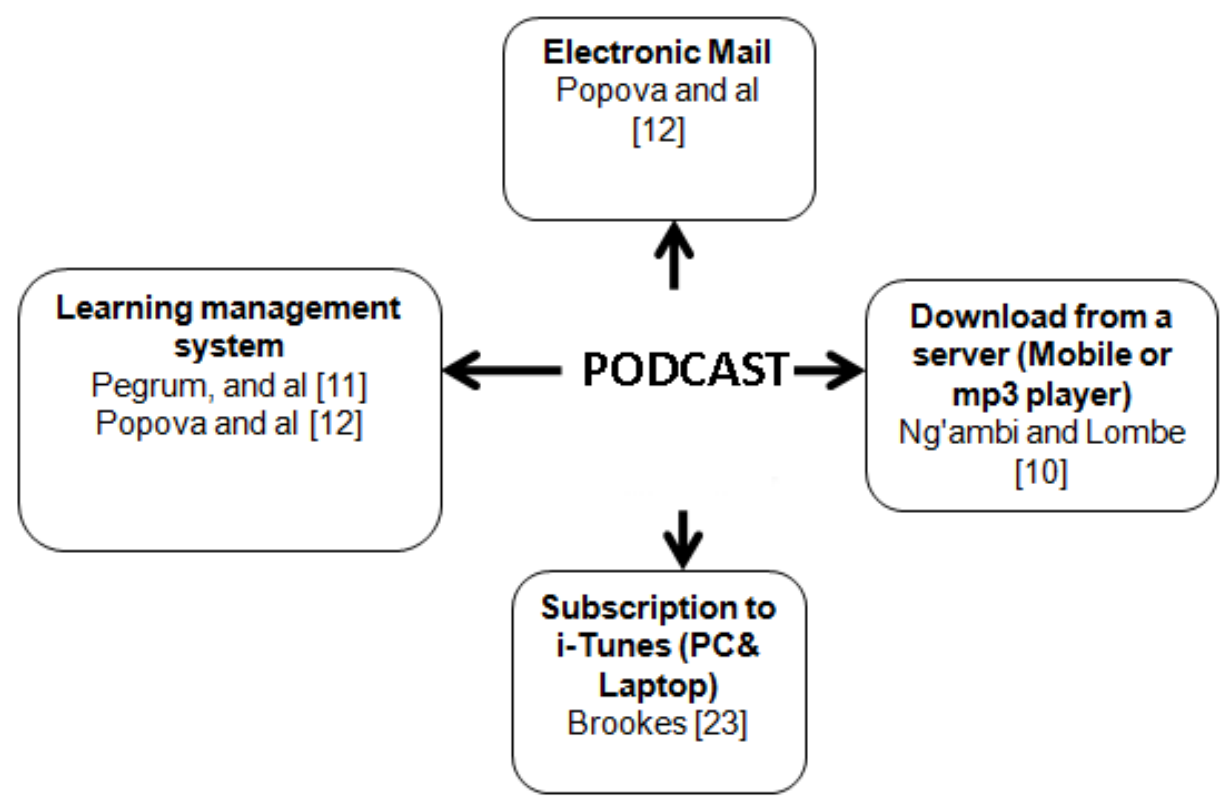

Figure 2: Techniques used to submit and share podcasts

\section{CONCLUSIONS}

From the studies it is clear that Action research is best choice for investigating the use of podcasting in the Education sector. This is so since it provides collaborative activity among colleagues searching for solutions to everyday, real problems experienced in schools, or looking for ways to improve instruction and increase student achievement.

Different approaches can be adopted when conducting the studies on podcasting however the choice must be informed by the objectives. The choice of an approach should also guide researchers in determining the best tools to be used in data collection. The utilization of podcasts as tools for developing strategic knowledge in teaching of practical subjects e.g. Computer programming, Computer Aided Design etc need to be investigated further. Apart the use of the data collection tools identified from previous studies the use of methods such as focus groups discussions should be explored. Such a method will best suited in situations where podcasting is used for collaborative learning among students. There is also need for further work to explore benefits of adopting specific approaches in the investigating the use of podcasting in Higher Education in different contexts.

This research also points the need to incorporate other techniques of sharing of podcasts among students and this would include use of Bluetooth is a free wireless technology standard for exchanging data over short distances and will increase the access to the resources.

\section{REFERENCES}

[1] Alpay E. and Gulati S. 2010. Student-led podcasting for engineering education. European Journal of Engineering Education, $35: 4, \quad$ pp. 415-427, DOI: 10.1080/03043797.2010.487557

[2] Chan W.M et al 2011. Students' Perceptions of and Attitudes towards Podcast-Based Learning - A Comparison of Two Language Podcast Projects, Electronic Journal of Foreign Language Teaching, Vol. 8, Suppl. 1, pp. 312-335

[3] Billingham, C., Gragg M. and Bentley G. 2013. Internationalization: From Concept to Implementation,
Higher Learning Research Communications - December $2013\{$ 166-526-1-PB.pdf \} Vol 3 page 4 http://journals.sfu.ca/liu/index.php/HLRC/article/downlo $\mathrm{ad} / 166 / 127$

[4] Jenkins, S., Goel, R., \& Morrell, D. S. 2008. Computerassisted instruction versus traditional lecture for medical student teaching of dermatology morphology: a randomized control trial. Journal of the American Academy of Dermatology, 59(2), pp. 255-259.

[5] Khechine, H., Lakhal, S., \& Pascot, D. 2013. University Students' Perception of the Pedagogical Use of Podcasts: A Case Study of an Online Information System Course. Journal Of Education And Training Studies, 1(2), pp. 136-151. doi:10.11114/jets.v1i2.139

[6] Kirkwood, A., \& Price, L. 2005. Learners and learning in the twenty-first century: What do we know about students' attitudes towards and experiences of information and communication technologies that will help us design courses? Studies in Higher Education, 30, pp. 257-274. doi:10.1080/03075070500095689

[7] Klein, H. K., \& Myers, M. D. 1999. A set of principles for conducting and evaluating interpretive field studies in information systems. MIS Quarterly, 23(1), pp. 67-94. http://dx.doi.org/10.2307/249410

[8] Lee, K., Williams, M.K. \& Kim, K. 2012. Learning through social technologies: facilitating learning experiences with Web 2.0 social media. In P. Resta (Ed.), Proceedings of Society for Information Technology \& Teacher Education International Conference 2012 (pp. 560-565). Chesapeake, VA: AACE. Retrieved on March 11, 2014 from http://www.editlib.org/p/39630.

[9] Ng'ambi, D., and Lombe, A. 2012. Using Podcasting to Facilitate Student Learning: A Constructivist Perspective. Educational Technology \& Society, 15 (4), 181-192.

[10] Pegrum M., Bartle E, and Longnecker N. 2014. Can creative podcasting promote deep learning? The use of podcasting for learning content in an undergraduate 
science unit, British Journal of Educational Technology, British Educational Research Association doi:10.1111/bjet.12133

[11] Popova A, Kirschner P.A and Joiner R. 2013. Effects of primer podcasts on stimulating learning from lectures: How do students engage? British Journal of Educational Technology, Blackwell Publishing;Oxford UK doi:10.1111/bjet.12023

[12] Simões L \& Gouveia L. B. 2008. Web 2.0 and Higher Education: Pedagogical Implications. Proceedings of the 4th International Barcelona Conference on Higher Education Vol. 2. Knowledge technologies for social transformation, Barcelona: GUNI. http://upcommons.upc.edu/revistes/bitstream/2099/5736/ 1/12_pap_Simoes.pdf

[13] UNESCO 2009. Need for technology in higher education. 2009 World conference on Higher Education http://www.unesco.org/fileadmin/MULTIMEDIA/HQ/E D/ED/pdf/ WCHE_2009/FINAL\%20COMMUNIQUE \%20WCHE\%202009.pdf

[14] Watts, H. 1985. When teachers are researchers, teaching improves. Journal of Staff Development, 6 (2), 118-127.

[15] Yeh C. 2013. An Investigation of a Podcast Learning Project for Extensive Listening, Language Education in Asia, 2013, 4(2), pp. $135 \quad$ - 149. http://dx.doi.org/10.5746/LEiA/13/V4/I2/A04/Yeh

[16] Yizengaw T. 2008. Challenges of Higher Education in Africa and Lessons of Experience for the Africa - U.S. Higher Education Collaboration Initiative. National Association of State Universities and Land-Grant Colleges.

http://www.uhasselt.be/Documents/UHasselt_EN/Interna tional/Lezing\%20N-Z\%202013/challegnes_in_africa.pdf

[17] Yorke, M. 2003. Formative assessment in higher education: Moves towards theory and the enhancement of pedagogic practice. Higher Education, 45,pp. 477501. doi:10.1023/A:1023967026413
[18] Towards Maturity 2013. New Learning Agenda, http://towardsmaturity.org/shop/wpcontent/uploads/2013/11/New-Learning-Agenda-TMBenchmark-2013-Full-Report-Nov-25th.pdf

[19] Tyagi S. 2012. Adoption of Web 2.0 technology in higher education: A case study of universities in National Capital Region - India, International Journal of Education and Development using Information and Communication Technology (IJEDICT), 2012, Vol. 8, Issue 2, pp. 28-43.

http://ijedict.dec.uwi.edu/include/getdoc.php?id=5205\&a rticle $=1452 \&$ mode $=$ pdf

[20] Williamson J. 2006. If You Can Teach, You Can Podcast: Get Started Today, BruinTech Seminar, Unoversity of Carlifornia.

http://www2.oid.ucla.edu/units/tlc/tectutorials/casting/po dcastingslides.pdf

[21] Taylor, L., \& Clark, S. 2010. Educational Design of Short, Audio - only Podcasts: the Teacher and Student experience. Australasian Journal of Educational Technology, 26 (3), pp. 386 -399.

[22] Brookes M. 2010. An evaluation of the impact of formative feedback podcasts on the student learning experience. Journal of Hospitality, Leisure, Sport \& Tourism Education. Vol.9, No. 1;ISSN: 1473-8376

http://www.new1.heacademy.ac.uk/assets/hlst/documents /johlste/vol9no1/05AP238Brookes_final53to64.pdf

[23] Alvarez, R. 2002. Confessions of an information worker: A critical analysis of information requirements discourse. Information and Organization, 12, pp. 85 - 107.

[24] Lee, M., \& Chan, A. 2007. Reducing the effects of isolation and promoting inclusivity for distance learners through podcasting. Turkish Online Journal of Distance Education, 8(1), Article 7. 